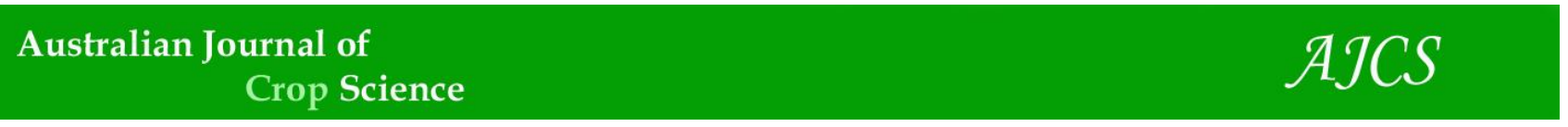

AJCS 14(08):1310-1318 (2020)

ISSN:1835-2707

doi: 10.21475/ajcs.20.14.08.p2589

\title{
Biomass growth and development in air-cured burley and flue-cured virginia tobacco varieties
}

\author{
Luis Felipe Boaretto*1, Fabricio Silva Coelho*1 , João Leonardo Corte Baptistella², Paulo Mazzafera ${ }^{2,3}$ \\ ${ }^{1}$ Souza Cruz LTDA, Av. Frederico Augusto Ritter, 8000 - Distrito Industrial, Cachoeirinha - RS, Brazil \\ Departamento de Produção Vegetal, Escola Superior de Agricultura “Luiz de Queiroz", Universidade de São Paulo, \\ Piracicaba, SP, Brazil \\ ${ }^{3}$ Departamento de Biologia Vegetal, IB, Universidade Estadual de Campinas, Campinas, SP, Brazil
}

\author{
*Corresponding authors: luis.boaretto@souzacruz.com.br; fabricio.coelho@souzacruz.com.br
}

Abstract

Research on the accumulation and partitioning of biomass in the tobacco cycle is scarce, particularly those comparing different varieties. The objective of this work was to study the partition of biomass in air-cured burley - ACB (BAT2101) and flue-cured virginia - FCV (CSC4704) varieties. In a greenhouse experiment, the two varieties were transplanted into pots containing a mixture of fine sand and substrate (1:1). Samples were taken for a period of 98 days, with 7 day intervals. In each harvest, dry mass and leaf area were measured, and specific leaf mass, leaf area ratio, relative growth rate, net assimilation rate, and root to shoot ratios were estimated. The data showed that carbon partitioning in plants of both varieties is influenced by root growth, which was $50 \%$ higher in ACB by the end of the experiment. The higher accumulation of mass in the roots of this variety may be related to the fact that it requires more nitrogen than virginia and, therefore, it could be a mechanism for increased uptake of this element. ACB also had higher specific leaf mass than FCV, which may be related to the body of ACB. This information is important for choosing varieties adapted for field conditions, as well as for the genetic improvement of tobacco. Furthermore, from the point of view of crop management, this knowledge may provide useful information for maximizing leaf growth.

Keywords: Carbon partition; growth analysis; leaf area; root growth; specific leaf mass; tobacco quality. Abbreviations: ACB_Air-Cured Burley; DAT_Days after transplanting; DM_dry mass; FCV_Flue-Cured Virginia; LA_maximum leaf area; LAR_leaf area ratio; NAR_net assimilation rate; RGR_relative growth rate; SLM_specific leaf mass.

\section{Introduction}

Currently, the Nicotiana genus is economically ranked as the most important among non-food plants (Creek et al., 1994). It is used in the production of cigars, cigarettes, pipe tobacco and so-called "smokeless tobacco", and is consumed by hundreds of millions of people worldwide (Lewis, 2011). As a result, there is a significant interest in breeding programs of the Nicotiana spp. species, as well as other related biotechnology projects. In general, the objective of any new variety development program focuses on productivity, quality and resistance against pests and diseases. In addition to these major phenotypic characteristics, the Nicotiana species have contributed to tobacco breeding programs by allowing the improvement of techniques such as genetic introgression, hybridization control, ploidy manipulation and somaclonal variation found in plant tissue culture (Lewis, 2011). The distinction between tobacco classes currently sold, is based on different curing methods and biochemical characteristics, which are divided into 7 groups: Flue-Cured Virginia (FCV), Air-Cured Burley (ACB), Oriental, Cigar, DarkAir Cured, Dark-Fire Cured and Primitive Tobaccos. The most widely grown and regularly used varieties in tobacco products are of the FCV and ACB classes (Fricano et al.,
2012). Nicotiana tabacum L. appears to be a natural hybridization event between Nicotiana sylvestris and Nicotiana tomentosiformis. The genetic background of FCV and $A C B$ varieties is very similar and, together with the Oriental class, represent the basis of the diversity presented in the N. tabacum species (Fricano et al., 2012).

Anatomically, FCV consists of leaf insertions perpendicular to the plant stem, while ACB has an insertion angle of less than 90 degrees, which reflects an efficiency in capturing sunlight and, consequently, partitioning of the photoassimilated carbon. Both varieties have good productivity, but $A C B$ varieties usually need $30 \%$ more nitrogen fertilizer compared to FCV (unpublished data technological package of Souza Cruz LTDA). Another important point to note is the harvesting and curing methods for these varieties. FCV is cured according to leaf physiological maturity, i.e. leaves are harvested from the base to the top of the plant. After, the leaves are subjected to curing in a barn with forced circulation of hot air for approximately 5 to 7 days. The ACB tobacco plants are harvested in their entirety (leaves + stem) followed by suspension in the barns, using constructions which facilitate 
the circulation of ambient air. On average, the curing period of $A C B$ lasts from 40 to 50 days and is extremely dependent on the local microclimate to achieve the demanded quality standards.

As the leaves are the principal product of tobacco farming, it is of interest to produce more leaves and with higher quality, so their size is an important component to be evaluated (Dyulgerski Y, Radoukova T, 2016). It is generally believed that cell division, in various leaf tissues ceases before the leaf has reached $1 / 4$ of its final area. Therefore, subsequent growth would occur due to cell expansion, during which the concentration of substances related to quality are defined (Darkis et al., 1952; Garner, 1946; Moseley et al., 1951). This leaf growth pattern explains the importance of water during tobacco leaf formation, and prolonged stress could lead to a $70-80 \%$ crop loss (Recep and Ulviye, 2006).

Tobacco growth, yield and quality depend on the environment and crop management, but also on the characteristics of each variety (Beljo et al., 1999; Jiang et al., 2016). Dry mass accumulation in the tobacco plant tends to follow a sigmoidal curve (Moustakas and Ntzanis, 2005), with leaf production varying according to the variety, spacing, fertilizer application and other factors related to crop and environment management (Garner, 1946). Interestingly, slow growth favours leaf quality (McCants and Woltz, 1967).

Despite extensive and robust literature on leaf quality of tobacco varieties (Mendell et al., 1984, United States Department of Agriculture, 1989), studies on the accumulation and partitioning of biomass over the productive cycle are scarce, especially when comparing tobacco varieties. Such information would be important, not only for choosing varieties adapted to the production environment, but also for use in the genetic improvement of the crop. Moreover, from the point of view of crop management, this knowledge could provide useful information for maximizing leaf growth.

The objective of this work was to understand the development and partitioning of biomass in two tobacco varieties, FCV and ACB, over the productive cycle. Together, these two varieties are responsible for more than $90 \%$ of global tobacco production for cigarettes and, in the cigarette, represent $80 \%$ of the tobacco blends (Risteski et al.,

2018).

\section{Results}

\section{Plant height, LA and LAR}

The height of plants of the FCV variety was always greater, throughout the experiment, than ACB. In general, the height of the two varieties presented similar behavior, increasing over time and reaching their maximum of 84 DAT (Figure 1). After plant topping, at 65 days for ACB and 73 days for FCV, there was still a small increase in height.

The LA of FCV was around 2 times greater than ACB. After topping, the LA tends to stabilize in both varieties (Figure $2 A)$. The LAR (Figure 2B), which provides the ratio of leaf area and total plant mass, showed a decrease for both varieties, but the difference between the two varieties in the beginning of the experiments was smaller at the end. This is evident in Figure $2 \mathrm{~B}$, when looking at the inclination of the trend lines adjusted for both varieties. The inclination of FCV is greater when compared to ACB.

\section{DM accumulation and allocation}

The DM of leaves and stem, as well as total DM, showed that mass accumulation was greater in FCV (Figures 3A, 3C, $3 D$ ). Root DM, however, was greater in $A C B$ (Figure $3 B$ ). At 98 days, the root $D M$ of $A C B$ was around $50 \%$ higher than FCV. Also, in Figure $3 B$, for both FCV and $A C B$, the points subsequent to topping indicate a greater accumulation of $D M$ in the roots. A more pronounced increase was seen in $A C B$. Leaf separation in lamina (Figure $4 A$ ) and stem (Figure 4B) showed that DM accumulation was similar in both varieties. However, the stem DM of virginia tended to become greater than burley at around 98 days, demonstrating that its participation in leaf mass was greater in this type of tobacco. The calculation of the percentage of DM of each organ in relation to the total DM of the plant, shows that despite the increase in LA in both varieties, the $\mathrm{DM}$ of the lamina fell during the growth of the plant (Figure $5 \mathrm{~A})$. On the other hand, the plants invest more carbon in the stem (proportionally to the time of growth) up until around 60 days close to topping. After this crop practice, there is a decrease in the stem DM (Figure 5B). As the plants grew in height, DM allocation in the stalk was continuous (Figure 5C). Furthermore, it has also been verified that after topping, both varieties produce more root biomass, indicating a higher investment of photoassimilates on roots proportionally to the shoot (Figure 5D). The SLM of the two varieties showed that, regardless of whether the whole leaf (lamina + stem) or only the lamina was used for the calculation, the leaves of FCV (Figure 6A) had a lower value, indicating that they may be thinner than ACB (Figura 6B).

The ratios between the DM root and the DM shoot, as well as between the DM root and the DM leaves showed that the $A C B$ root system (Figure $7 A$ ) was proportionally greater than that of FCV (Figura 7B). Moreover, in both varieties there was an increase in this ratio after topping, however $A C B$ achieves higher values than FCV, showing its greater investment in the roots. Plant growth The RGR, calculated either with total DM (including roots; Figure $8 \mathrm{~A}$ ) or with the DM shoot (excluding roots; Figure $8 \mathrm{~B}$ ), showed quite similar behavior, and this was the case for both varieties. On the other hand, NAR, showed higher values for $A C B$ over the whole period of the experiment (Figure 8C).

Discussion

\section{Plant development, growth and DM partitioning}

Few studies have evaluated DM partition in tobacco and, generally, conclude the study in a much shorter time when compared to this work. In most cases, an increase in height and the DM of the shoot is reported (Dahal and Vanlerberghe, 2018). For example, the data obtained from Dahal and Vanlerberghe (2018) spans across 48 days, and shows a decrease in the contribution of leaf DM to the total DM over the growth period of the plants.

Height and leaf area are intrinsic genetic characteristics of each variety and can be altered according to the environment or management to which they are subjected to 


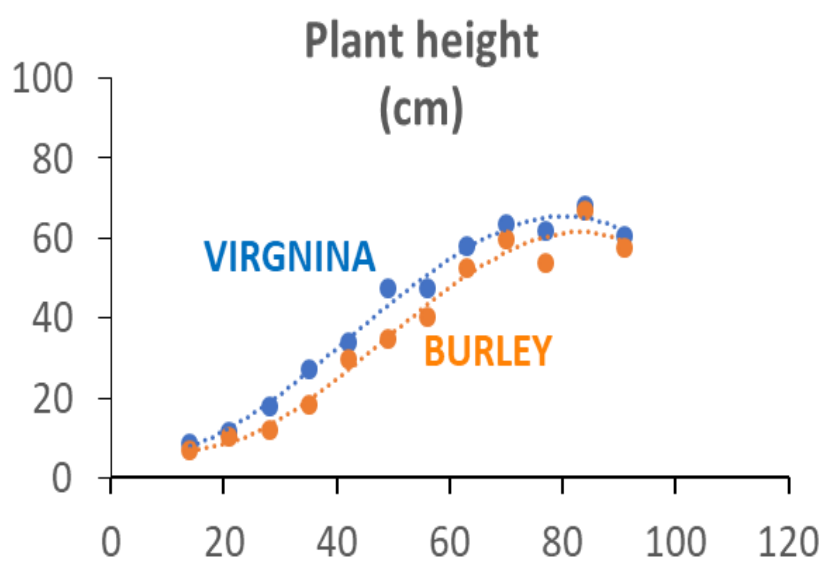

Fig 1. Plant height of the varieties Air-Cured Burley $\left(y=0.0003 x^{3}+0.048 x^{2}-1.127 x+14.54, r^{2}=0.98\right)$ and Flue-Cured Virginia $\left(y=0.0003 x^{3}+0.0036 x^{2}-0.339 x+6.38, r^{2}=0.99\right)$.
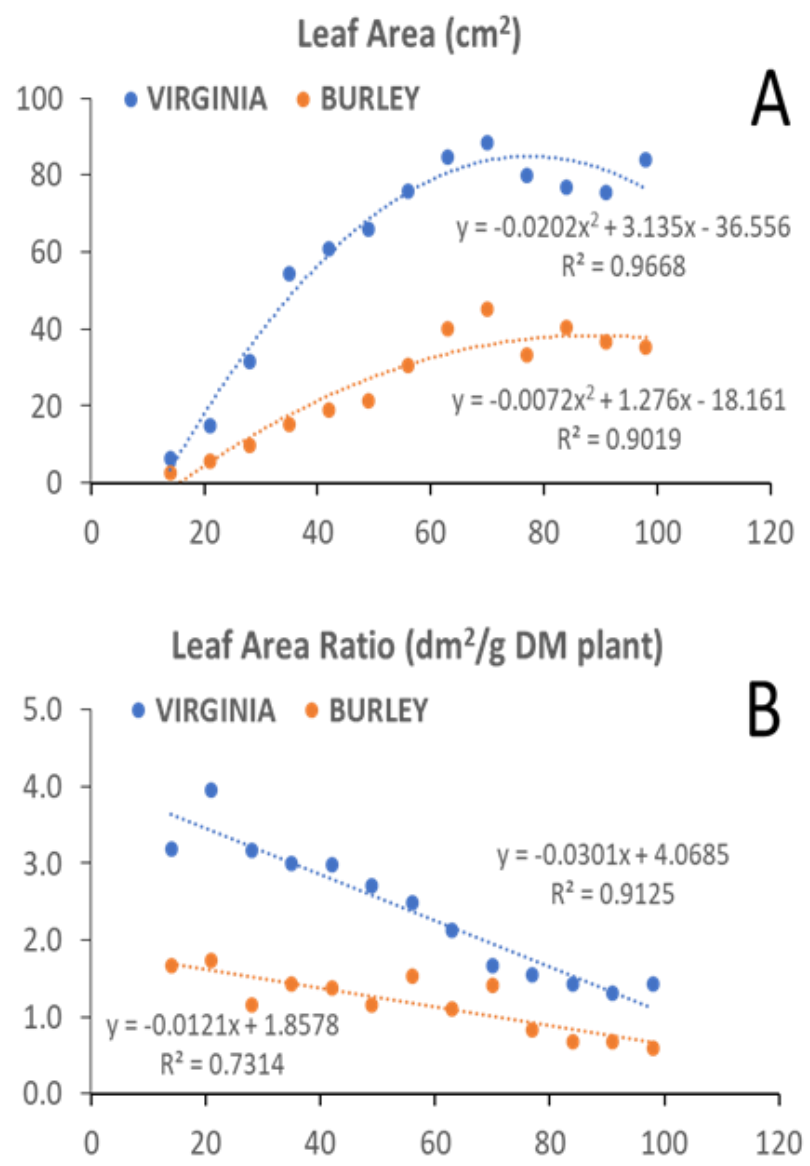

Fig 2. Total leaf area (A) and leaf area ratio (B) of plants of the varieties Air-Cured Burley and Flue-Cured Virginia. 

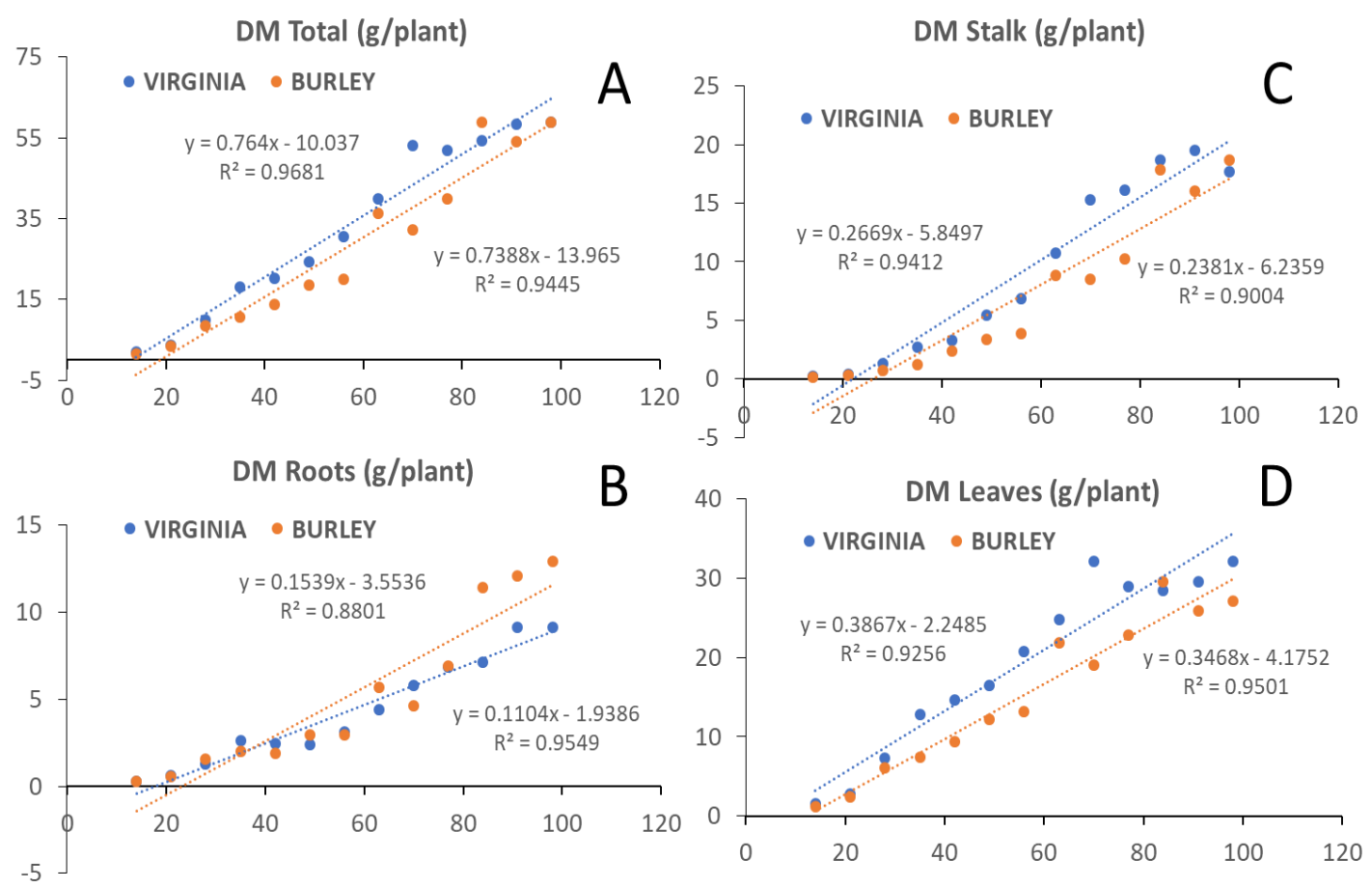

Fig 3. Dry mass of the plant (A), of the roots (B), of the stem (C), and of the leaves (D) of plants of the varieties Air-Cured Burley and Flue-Cured Virginia.
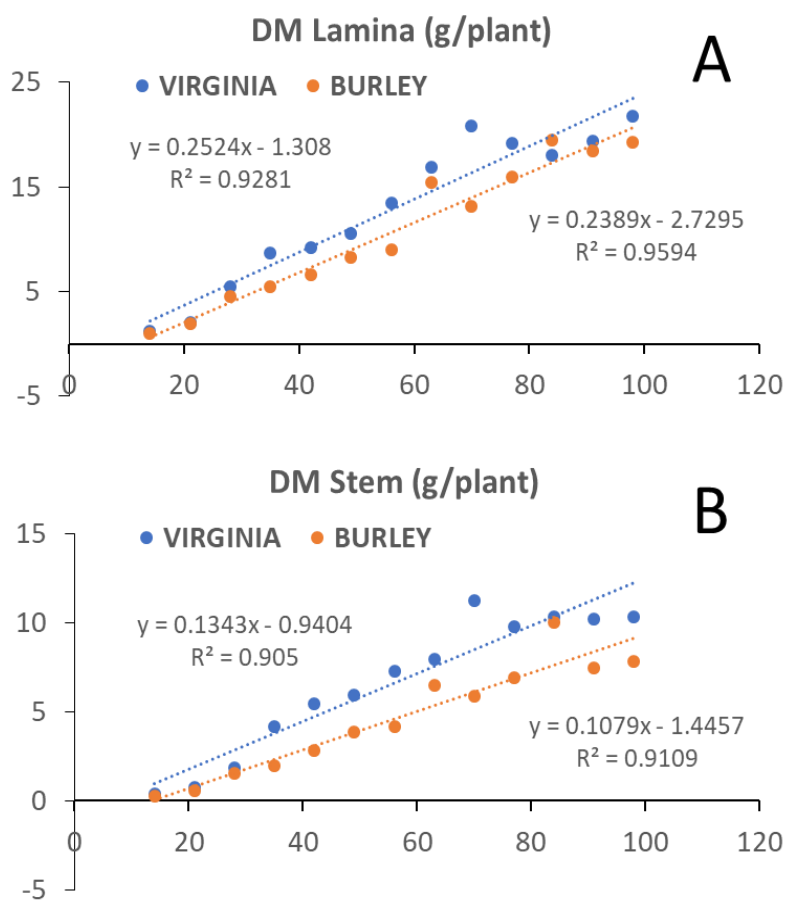

Fig 4. Dry mass of the leaf lamina (A) and the stems (B) of leaves of plants of the varieties Air-Cured Burley and Flue-Cured Virginia. 
\%DM Lamina

\%DM Stalk
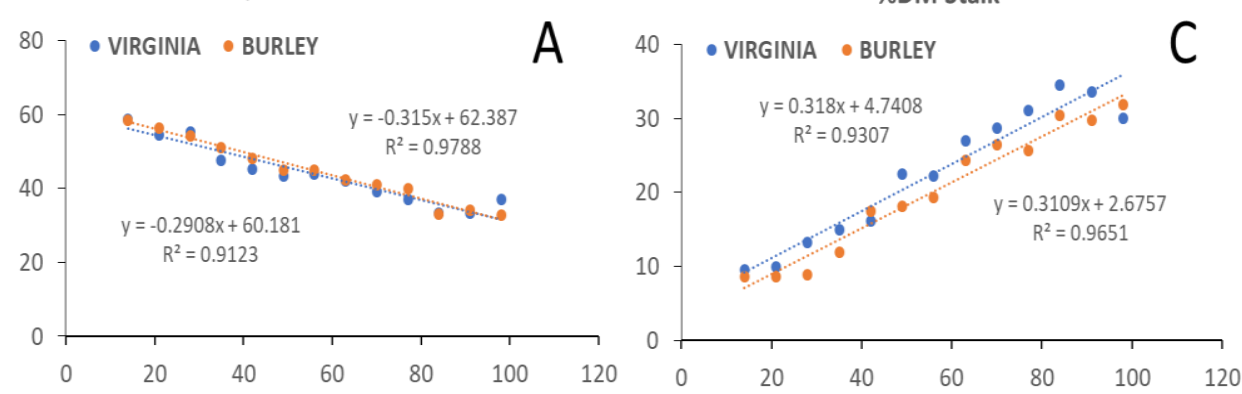

$\%$ DM Stem

B

$\%$ DM Roots
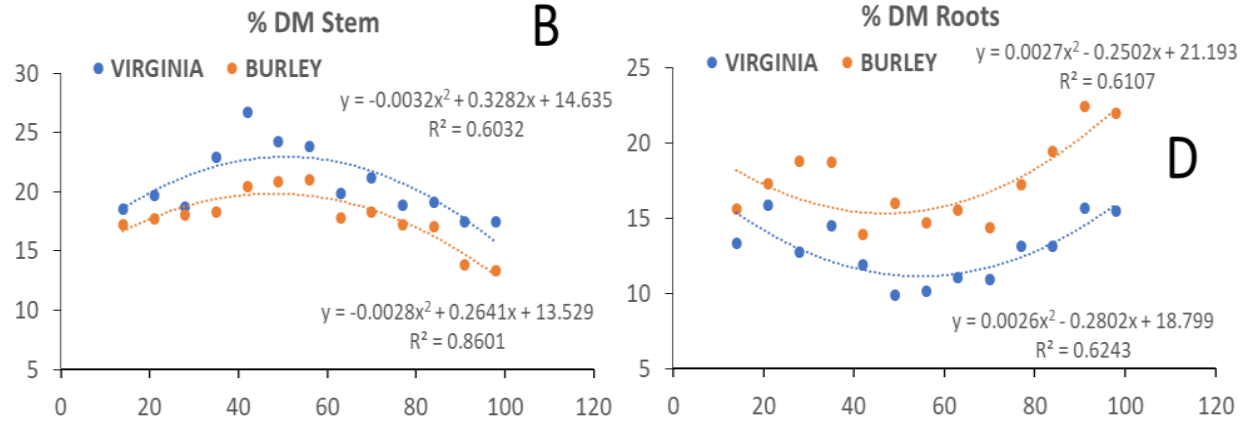

Fig 5. Percentage of dry mass of the lamina (A), the stem (B), the stalk $(C)$ and the roots $(D)$ in relation to the total plant DM in plants of the varieties Air-Cured Burley and Flue-Cured Virginia.
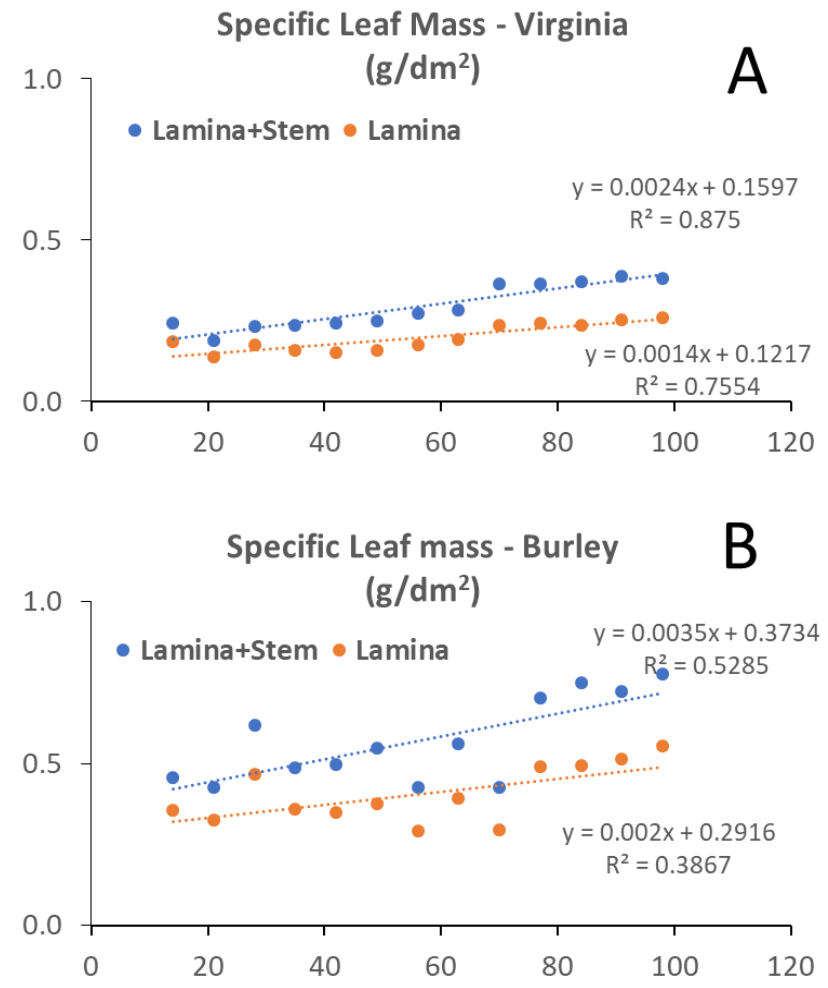

Fig 6. Specific leaf mass of leaves from plants of the varieties Flue-Cured Virginia (A) and Air-Cured Burley (B), calculated with the total leaf mass (lamina + stem) or only with the lamina. 

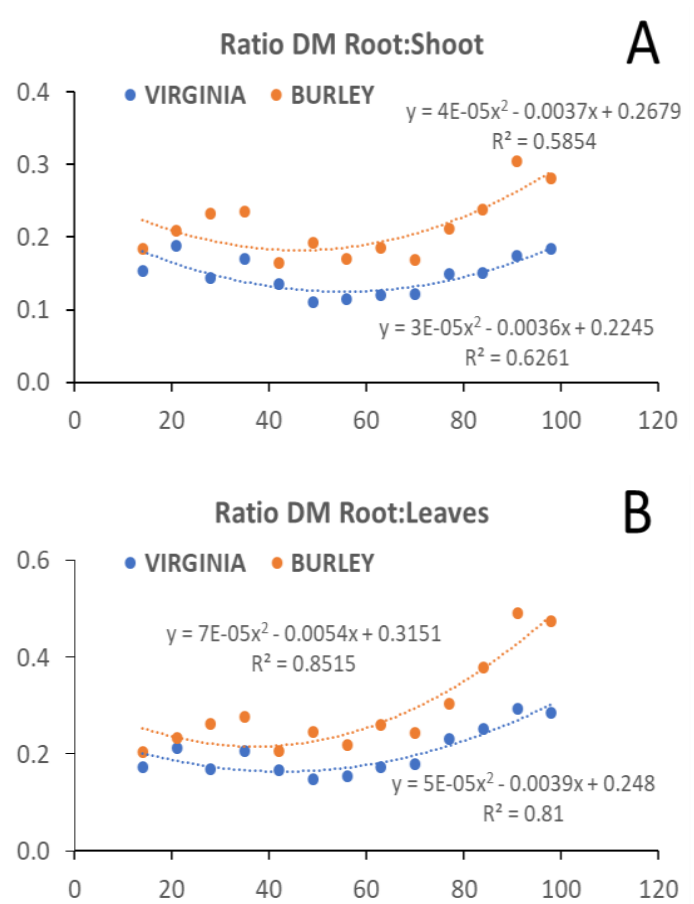

Fig 7. Ratios of the root:shoot (lamina+stalk+stem) (A) and the root:leaves (lamina+stem), (B) dry mass ratio of plants of the varieties Air-Cured Burley and Flue-Cured Virginia.
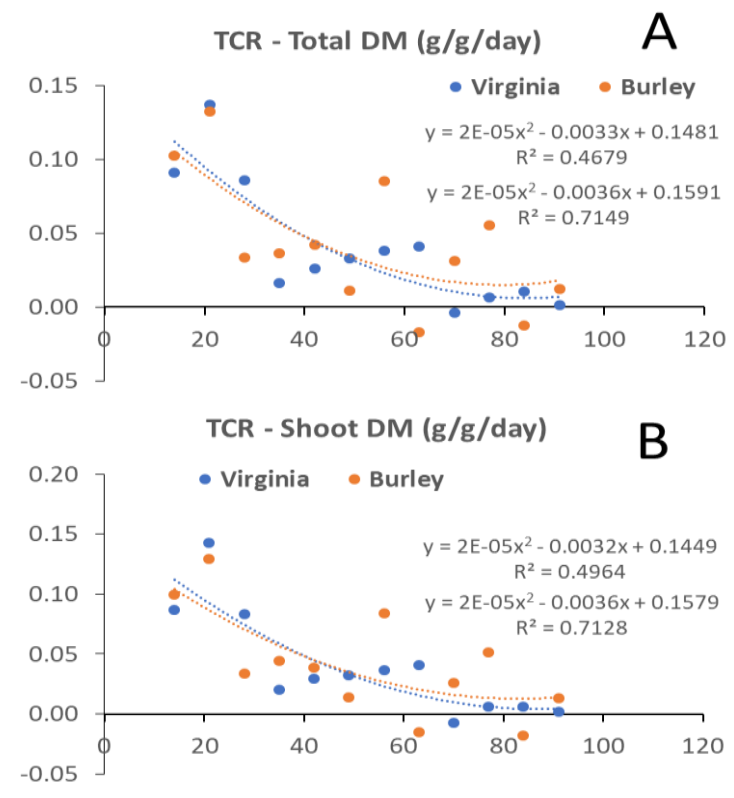

NAR (g/dm²/day)

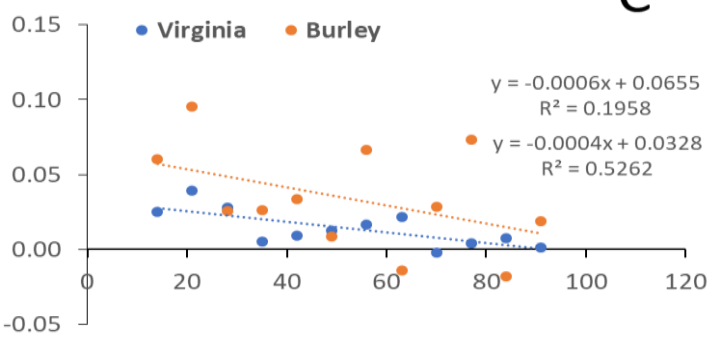

Fig 8. Relative growth rates based on the total plant mass (including roots; A) and the shoot (excluding roots; B), and the net assimilation rate (C) of plants of the varieties Air-Cured Burley and Flue-Cured Virginia. 
(Risteski et al., 2012, Risteski and Kocoska, 2018). In this study, tobacco plants of the two varieties were grown in the same conditions, so that the observed differences were as a result of genetic backgrounds. Although the two varieties did not show a significant difference in relation to height, they were highly contrasting in regard to LA (Figures 1 and 2). The virginia variety, which showed a larger LA than the burley variety, belongs to the tall plant tobacco group and is recognized for its large leaves (Risteski and Kocoska, 2018).

\section{Leaf area affects plant growth}

The RGR of a plant is the product of the LAR to the NAR. For many plants, the LAR is the main factor that causes variations in the RGR, as the LAR varies mainly as a function of the SLM (Atkin et al., 1996, Poorter and Remkes, 1990). The LAR indicates the photosynthetic surface per unit mass of the plant and serves as a measure of efficiency by which the plant uses its photosynthetic resources. As such, the LAR and the SLM data show two different growth adaptations within the two varieties studied, which present similar RGR levels. In other words, while the LAR was greater in virginia for all samplings, burley showed higher SLM. Virginia, therefore, allocates more resources for growth of the leaf area, while burley tobacco allocates more mass per unit leaf area which, at first, indicates thicker leaves.

Effects of topping on the growth and DM partitioning

Topping is a management practice of tobacco production to improve yield and quality of the leaves. The shoot apex is removed when the first flower of the inflorescence is blossoming (Hibi et al., 1994, Xi et al., 2005). Topping also seems to increase leaf size and mass, and thus the thickness of the leaves (Moore et al., 2013). Similar results were obtained in this study, since the SLMs of both varieties show an increase after 70 days, once topping had been carried out (see Figure 3). However, we are not aware of any comparative studies of tobacco varieties that correlate thickness with carbon partitioning throughout their development.

\section{Leaf anatomical structure effects on growth and allocation}

It has been found in oriental tobacco that there is a relationship between leaf size and cell size, with the larger leaves having the larger cells and that these cells are more loosely arranged (Wolf and Jones, 1944). Our interpretation is that the loose arrangement described in this work for oriental tobacco, may be related to a lower SLM, but this was not determined by the authors.

In a study with various Lolium perenne mutants (Wilson and Cooper, 1969), it was shown that the SLM was higher in thinner leaves that had small mesophyll cells. The chlorophyll content was also higher in these leaves. On the other hand, Hanba et al., (1999) studied the leaves of trees from a temperate forest in Japan and found that in the leaves of some plants with thicker mesophyll there was a tendency for higher SLM, a greater surface area of mesophyll cells exposed to the air from intercellular space per unit area, and a lower ratio of intercellular spaces to the whole mesophyll (mesophyll porosity). Such characteristics would explain the conductance of $\mathrm{CO}_{2}$ in the leaves and, consequently, variations in photosynthetic efficiency.
Therefore, variations in the anatomical structure of the tobacco leaf may be important in the way that they capture and allocate carbon in their tissue and organs. The importance of leaf anatomy for the physiology of photosynthesis is very well exemplified by differences seen in leaves developed under different light intensities, which have different anatomical characteristics (Terashima et al., 2005). Anatomical changes may have a big influence on the internal distribution of light in the leaves (scattering), which, in turn, could directly affect photosynthetic efficiency (Xiao et al., 2016).

The LAR of virginia at the end of the experiment was approximately two times greater compared to burley plants (Figure 2A). On the other hand, SLM was also approximately two times greater in burley plants (Figures $6 \mathrm{~A}$ and $6 \mathrm{~B}$, leaf + stem). Consequently, the RGR of both varieties was close. In addition to these variations, the sharpest drop of the LAR in virginia seems to be as a consequence of the LA growth pattern for this variety. The LA of burley stabilizes at around 80 days, while the LA of virginia shows a decline after 80 days. Therefore, the leaf structure of tobacco plants seems to be an interesting subject for observation, opening the possibility of its application in the improvement of this crop.

\section{Allocation to roots}

For both varieties, the greatest investment in roots from 6070 DAT may be related to topping. This practice is known to promote tobacco root growth (Davis and Nielson, 1999). There is also a known change in the standard of plant dry mass distribution and growth stimulation of upper leaves and roots after removal of the apical part of plants (Xi et al., 2008).

Because burley topping takes place 8 days before virginia, it could be argued that this explains the greater root mass in this variety. However, from 50 DAT onwards, a greater accumulation of mass for this variety had already been noted (Figure 3). Root production correlates positively with nicotine content in tobacco, and it is possible that greater root production explains the higher content of this alkaloid commonly found in the burley variety (Davis and Nielson, 1999).

\section{Materials and Methods}

\section{Plant material, installation and carrying out of the experiment}

The experiment was carried out in a greenhouse in the municipality of Cachoeirinha/Rio Grande do Sul/Brazil (29 $52^{\prime} 54^{\prime \prime} \mathrm{S}$; 51 $06^{\prime} 06^{\prime \prime} \mathrm{W}$; Altitude $33 \mathrm{~m}$ ) between March 2019 and July 2019. The varieties CSC4704 (FCV) and BAT2101 (ACB) of $N$. tabacum were used in the experiment. Seeds from the two varieties were sown individually in trays with $15 \mathrm{~cm}^{3}$ cells and kept for 55 days until reaching an adequate height for transplanting. They were transplanted into $1.5 \mathrm{~L}$ pots containing a mixture of fine sand and Carolina Soil substrate at a ratio of $1: 1(\mathrm{v} / \mathrm{v})$. Experimental design was completely randomized by blocks with 4 replicates. The plants were kept in the greenhouse under temperature control $\left(25^{\circ} \mathrm{C} \pm 3^{\circ} \mathrm{C}\right)$ and with daily watering. Two fertilizer applications were carried out each week with a 20-10-20 
formula (3 grams per plant). Due to differences in variety cycles, topping (removal of inflorescence) was carried out in two stages: at 65 DAT for ACB and 73 DAT for FCV. The experiment was completed with the last collection time at 98 DAT.

\section{Biometric evaluations and determination of dry mass (DM)}

The time interval for collections was defined and standardized over 7 days totaling 13 collections. In each collection, four plants from each variety were chosen at random to determine the width and length of each leaf of each plant individually, as well as the height of the plants. The leaves were then separated into main leaf nerves (stem) and lamina. The roots were washed in running water to remove substrate. Each part of the plant was dried separately in an oven at $65^{\circ} \mathrm{C}$ until a constant mass was reached. The total DM of the plant was calculated by adding the DM of the leaves, stem and roots. The leaf area was simply estimated by the product of the width and length measurements (Romano, 2001).

\section{Growth analysis}

In order to evaluate the growth of tobacco varieties, the following indices were calculated:

a) Specific leaf mass

b) Leaf area ratio

$$
\operatorname{SLM}\left(\mathrm{g} \cdot \mathrm{dm}^{-2}\right)=\frac{\text { leaves } D M}{\text { Total leaf area }}
$$

c)

$$
\text { LAR }\left(\mathrm{dm}^{2} \cdot \mathrm{g}^{-1}\right)=\frac{\text { Total leaf area }}{\text { Total DM }}
$$

\section{Relative growth rate}

$$
R G R\left(\text { g. day }{ }^{-1}\right)=\frac{(\ln C 2-\ln C 1)}{(T 2-T 1)}
$$

Where: $\operatorname{LnC}(n)$ is the natural logarithm of $D M$ in a given collection; $T(n)$ is the time, in days, when the collection was carried out.

\section{d) Apparent assimilation rate}

$$
=\left\lfloor\left\lfloor\frac{(C 2-C 1)}{(T 2-T 1)}\right\rfloor X\left\lfloor\frac{(\ln L A 2-\ln L A 1)}{(A 2-A 1)}\right\rfloor\right\rfloor
$$

Where: $C(n)$ is the total DM of a given collection; $T(n)$ is the time, in days, in which the collection was carried out; $\operatorname{LnLA}(n)$ is the natural logarithm of LA of the collection; and $\mathrm{AF}(\mathrm{n})$ is the leaf area, in $\mathrm{dm}^{-2}$, of the collection.

e) Ratio Dm root:shoot - dry mass of roots/dry mass shoot (laminas+stalk+stems)

$$
\text { Root: Shoot ratio }\left(g \cdot g^{-1}\right)=\frac{\text { Root } D M}{\text { Shoot DM }}
$$

Where: Shoot DM is the sum of lamina, stalk and stem DM.

f) Ratio DM root/leaves - dry mass of roots/dry mass of leaves (laminas+stems)

$$
\text { Root: Leaf ratio }\left(g \cdot g^{-1}\right)=\frac{\text { Root DM }}{\text { Leaf DM }}
$$

Where: Leaf DM is the sum of lamina and stem DM.

Conclusions

The data obtained here, supports previous research on burley and virginia tobacco varieties regarding shoot growth. However, our study shows that carbon partitioning in the two varieties is influenced by root growth, which is greater in burley. The higher accumulation of root mass in this variety may be related to the fact that it requires more nitrogen than virginia, and, therefore, could be a mechanism for increased uptake of this element. In addition, burley has greater SLM than virginia. A range of factors, including varietal differences, are known to influence leaf thickness, and that this characteristic is related to the thick body of cured tobacco leaves. Burley is known to have a larger body than virginia and we hypothesized that this could be related to the thickness of fresh leaf on the plant. However, this requires confirmation in different varieties of burley and virginia, cultivated under field conditions.

\section{Acknowledgments}

Paulo Mazzafera thanks The Brazilian National Council for Scientific and Technological Development (CNPq) for a research fellowship.

\section{References}

Atkin OK, Botman B, Lambers H (1996) The causes of inherently slow growth in alpine plants: an analysis based on the underlying carbon economies of alpine and lowland Poa species. Funct Ecol. 10:698-707.

Beljo J, Čavlek M, Budin T (1999) Effects of different growing practices on agronomic properties and usability of fluecured tobacco. Agriculture. 64:179-185.

Creek L, Capehart T, Grise VN, Division. USD of ACE (1994) U.S. tobacco statistics, 1935-92. Washington, DC: U.S. Dept. of Agriculture, Economic Research Service, Commodity Economics Division,

Dahal K, Vanlerberghe GC (2018) Improved chloroplast energy balance during water deficit enhances plant growth: More crop per drop. J Exp Bot. 69:1183-1197.

Darkis FR, Baisden LA, Gross PM, Wolf FA (1952) Flue-cured tobacco. Chemical composition of rib and blade issues. Ind Eng Chem. 44:297-301.

Davis D, Nielson MT (1999) Tobacco : production, chemistry and technology. Page Tobacco : Production, Chemistry and Technology. 131-133 p

Dyulgerski Y, Radoukova T (2016) Inheritance of the sizes of leaves in burley and virginia tobacco hybrid combinations. I. Length of leaves. Sci Technol. V:27-31.

Fricano A, Bakaher N, Del Corvo M, Piffanelli P, Donini P, Stella A, Ivanov N V, Pozzi C (2012) Molecular diversity, population structure, and linkage disequilibrium in a worldwide collection of tobacco (Nicotiana tabacum L.) germplasm. BMC Genet. 13:18.

Garner WW (1946) The production of tobacco. Philadelphia: Blakiston

Hanba YT, Miyazawa S-I, Terashima I (1999) The influence of leaf thickness on the $\mathrm{CO} 2$ transfer conductance and leaf stable carbon isotope ratio for some evergreen tree species in Japanese warm-temperate forests. Funct Ecol. 13:632-639. 
Hibi N, Higashiguchi S, Hashimoto T, Yamada Y (1994) Gene expression in tobacco low-nicotine mutants. Plant Cell. 6:723-735.

Jiang HL, Xu C, Wang D Bin, Gen LN, Zhao M, Zhu XW (2016) Effect of tobacco leaf width/length ratio on tobacco quality: a case study in the Chongqing tobacco production area. Aust J Crop Sci. 10:1455-1459.

Lewis RS (2011) Nicotiana. Pages 185-208 in Wild crop relatives: genomic and breeding resources

McCants CB, Woltz WG (1967) Growth and mineral nutrition of tobacco. Adv Agron. 19:211-265.

Mendell S, Bourlas EC, DeBardeleben MZ (1984) Factors influencing tobacco leaf quality: an investigation of the literature. Beitrage zur Tab Int Contrib to Tob Res. 12:153167.

Moore JM, Bertrand P, Jones D, Givan WD, Summer $P$, Harris GH, Kightlinger KD, Rains CG (2013) Georgia tobacco grower's guide. $212 \mathrm{p}$

Moseley JM, Harlan WR, Hanmer HR (1951) Burley tobacco relation of the nitrogenous fractions to smoking qualities. Ind Eng Chem. 43:2343-2347.

Moustakas NK, Ntzanis H (2005) Dry matter accumulation and nutrient uptake in flue-cured tobacco (Nicotiana tabacum L.). F Crop Res. 94:1-13.

Poorter H, Remkes C (1990) Leaf area ratio and net assimilation rate of 24 wild species differing in Relative growth rate. Oecologia. 83:553-559.

Recep C, Ulviye C (2006) Growth and dry matter accumulation dynamics of flue-cured tobacco under different soil moisture regimes. J Agron. 5:79-86.

Risteski I, Kocoska K (2018) Comparative analysis of quantitative traits in some Virginia tobacco varieties and lines. Tobacco. 68:26-34.
Risteski I, Kocoska K, Gveroska B (2012) Results of the investigation on some bio-morphological characteristics of domestic and introduced varieties of Burley tobacco. Tobacco. 62:13-21.

Risteski I, Kocoska K, Pelivanoska V (2018) Examination and analysis of yield, quality and economic effect within varietes of burley tobacco. J Agriculture For. 64:64-72.

Romano MR (2001) Fotossíntese e biossíntese de aminoácidos em plantas transgênicas de tabaco (Nicotiana tabacum L.) que expressam o gene lhcbl*2 de ervilha

Terashima I, Hanba YT, Tazoe Y, Vyas P, Yano S (2005) Irradiance and phenotype: comparative eco-development of sun and shade leaves in relation to photosynthetic $\mathrm{CO} 2$ diffusion. J Exp Bot. 57:343-354.

United States Department of Agriculture (1989) Official standard grades for flue-cured tobacco (U.S. types 11, 12, 13, 14 and foreign type 92). Page 36 The tobacco inspection act.

Wilson D, Cooper JP (1969) Apparent photosynthesis and leaf characters in relation to leaf position and age, among contrasting Lolium genotypes. New Phytol. 68:645-655.

Wolf FA, Jones EF (1944) Comparative structure of green leaves of oriental tobacco at different levels on the stalk in relation to their quality upon curing. Bull Torrey Bot Club. 71:512-528.

Xi X, Li C, Zhang F (2008) Tobacco plants can use nitrogen taken up before mechanical wounding to synthesize nicotine afterwards. Plant Signal Behav. 3:87-90.

Xi XY, Li CJ, Zhang FS (2005) Nitrogen supply after removing the shoot apex increases the nicotine concentration and nitrogen content of tobacco plants. Ann Bot. 96:793-797.

Xiao Y, Tholen D, Zhu X-G (2016) The influence of leaf anatomy on the internal light environment and photosynthetic electron transport rate: exploration with a new leaf ray tracing model. J Exp Bot. 67:6021-6035. 